\title{
SIMPLE AND SAFE HEPARIN REGIMEN FOR ACUTE ISCHAEMIA
}

\author{
P. R. M. BITTENCOURT* \\ S. PADILHA * \\ S. MAZER *
}

The role of acute anticoagulation in ischaemic cerebrovascular disease is complex. It is well established with respect to preventing further embolization in cardiogenic cerebral embolism 4,8,11. When there is occlusive disease of the supra-aortic or intra-cranial vessels producing thromboembolism of the brain, and specially in cases in which surgery is not recommended, the risk/benefit ratio is not well defined. No controlled studies of the efficacy or of the rate of complications of acute anticoagulation in cerebro-vascular disease have been reported since the advent of computerized axial tomography. The earlier studies became obsolete since it became clear that this method detects ischaemic and haemorrhagic infarction as well as hematomas, avoiding use of anticoagulants in haemorrhagic disease 12. Although aspirin has been demonstrated $t_{0}$ be efficient in the prevention of recurrence of transient ischaemic attacks 5,8 , the physician admitting a patient with the recent onset of a stable or a fluctuating vascular neurological deficit will be in difficulty to decide on the utilization of anticoagulation. Transient ischaemic attacks of recent onset, for example, may be followed by a completed stroke, the greatest risk occurring in the first week 10. The time between admission and the completion of the full work up needed by such patients, which includes cardiac and vascular investigations not immediately available at all hospitals, is usually of the order of days rather than hours. On the other hand computerized axial tomography is becoming very common all over the world and may be carried out soon after the patient is admitted, without any worsening of prognosis.

In this study we have evaluated the risk of complications of a simple method of administration of heparin to patients with acute ischaemic cerebrovascular disease, specifically with respect to age and arterial hypertension, which have been traditionally considered to be contra-indications for anticoagulant use. Heparin regimen - The clearence of heparin from the blood stream is exponential and dose-dependent. The half-life at dosages of $100 \mathrm{IU}$ per kilogram is around 152 minutes?. It thus follows that intermittent regimens in which $5000 \mathrm{IU}$ are given at intervals of 4 or 6 hours will produce a very high blood level for between one and two hours, when the coagulation time is infinite

Hospital Nossa Senhora das Gracas, Curitiba; *Unidade de Neurologia Clinica: ** Unidade de Tomografia Axial Computadorizada. 
and the risk is very high 7 . In fact it has been demonstrated that the frequency of serious bleeding during intermittent administration is above $10 \% 13$. In continuous infusion the peaks in blood level are avoided, decreasing serious bleeding to about $1 \% 13$. Deykin reviewed a number of studies on the complications and efficacy of heparin regimens 2 . In a prospective study carried out by his group 72 patients were given intermittent intravenous injection regulated by activated partial thromboplastin time (APTT); 68 patients were given intermittent intravenous injection with fixed doses; a further group of 69 patients were given intravenous infusion with the dose regulated by APTT. The mean heparin dose was $31700 \mathrm{IU}$ in the first group, $35600 \mathrm{IU}$ in the second group and $24500 \mathrm{IU}$ in the third group. Recurrences occurred in one case in each group. Major bleeding complications occurred in 6 patients in the first group, 7 in the second and one patient in the third group. Measuring the efficacy of anti-coagulation by the recurrence rate there is no difference in the three regimens. Considering the number of bleeding complications as evidence of peaks of intermittent anticoagulation continuous infusion is the better regimen. It should be emphasized that there is a great difference of dose between the three regimens, and that the lesser number of complications with continuous infusion may also be related to the dose utilized, which was $2 / 3$ of the two other regimens. Since infusion pumps are not generally avaiable in general hospitals in less developed countries we decided to use a safe and simple approach, i.e., to give intravenously a total dose of 20000 IU daily, divided in doses of 2500 IU every three hours.

\section{PATIENTS AND METHODS}

All patients admitted to the Clinical Neurology Unit during the period of the study with a diagnosis of acute and recent ischaemic cerebro-vascular disorder were included. These patients form part of a large on-going study on ischaemic cerebrovascular disease (1). Diagnostic categories included in the study were cerebral embolism of cardiac or carotid origin and carotid or intra-cranial thromboembolic disease. The diagnosis was based on clinical presentation of recent ischaemic infarction (stable neurological deficit), progressive infarction (fluctuating neurological deficit) or recurrent severe transient ischaemic attacks. In all cases computed tomography needed to be compatible. A diagnosis of cardiogenic embolism was made when computed tomography showed multiple recent ischaemic areas or multiple ischaemic areas not suggestive of lacunes or Binzwanger's disease in patients with cardiomiopathy or when there was clinical evidence of systemic embolization. The diagnosis of supra-aortic artery to artery embolization was made when appropriate abnormalities in upper limb or cervical pulses could be detected. The diagnosis of carotid occlusion was made with the picture of a progressive infarct with an appropriate cervical bruit. The diagnosis of intra-cranial thromboembolic phenomena was made by exclusion when a cardiac or carotid source of emboli could not be detected clinically or by auxiliary investigation. All patients admitted to the study had a full blood count, sedimentation rate, creatinine, blood sugar, syphilis serology, chest X-ray, eletrocardiogram and computerized tomography, Holter monitoring of electrocardiography, ecocardiogram, ventriculography, aortography, 
selective catheterization of supra-aortic branches or other tests were done as necessary Blood pressure was monitored every three hours. An effort was made to control blood pressure progressively over a period of a few hours after initiation of heparin.

The anticoagulation regimen was 2500 IU given intravenously every three hours until the clinical picture was defined. In case thromboembolic phenomena persisted the dose was raised to 5000 IU every 4 hours. If no surgically correctable source of emboli was detected, and the patient was thought to have made an improvement on heparin, he was put on coumarin anticoagulants.

\section{RESULTS}

A total of 27 males and 23 females entered the study. Their age was $57 \pm 14$ (mean \pm standard deviation) years with a range of 23 to 83 years. Their clinical presentations were recurrent severe transient ischaemic attacks in 11 cases and recent or progressive cerebral infarction in 39. The presumed diagnosis were cardiogenic embolism in 22 cases; carotid occlusive disease in 8 cases; carotid plaques (proved by angiography) in three cases; fat embolism in one case and intra-cranial thromboembolic disease in 16 cases. The cerebral arterial zones involved as determined clinically or by computerized tomography were the left middle cerebral in 21 cases; the right middle cerebral in 12; the posterior cerebrals (right + left) in 4; the basilar territory in 5 and multiple arterial zones in 8 cases. Of the 22 patients with embolization of cardiac origin there was one with complete atrial-ventricular block, one with isolated atrial fibrillation and one with isolated ventricular premature contractions. There were two patients with atrial fibrillation and cardiomegaly; two patients with atrial fibrillation, ventricular premature contractions and cardiomegaly; two patients with cardiomegaly and mixed premature contractions; and 8 patients with cardiomegaly only. There was one patient with mitral stenosis with ectopic beats, and another patient with aortic insufficiency and stenosis. One patient had Chagas' disease and a further patient had an aneurism of the left ventricle. Thirty of the patients had computerized tomography before starting heparin and 17 after. In two patients computerized axial tomography was not carried out because of an early death, and in one because a technical probiern delayed the exam until the patient had had arteriography and surgical excision of a carotid plaque. Of the 6 patients who had angiography carotid plaques were demonstrated in three. One patient had aortography and ventriculography with the demonstration of a ruptured tendinous chord which was corrected surgically. Two patients had coronary and ventricular studies but were considered inoperable. Two patients had ecocardiograms which were non-contributory. Three patients had holter monitoring of electrocardiogram which showed arrythmias. One patient had a lumbar puncture which showed a clear cerebro-spinal fluid. The initial blood pressure was below $160 / 95$ in 33 patients, below $180 / 100$ in 10 patients, below $190 / 130$ in 3 , and above $190 / 131$ in 4 cases.

Twenty-one patients received the 20000 IU daily regimen for between one and 5 days. Twenty-two patients received it for between 6 and 10 days, three for between 11 and 15 days and 4 for between 16 and 21 days. The mean time of exposure to heparin was $6.4 \pm 4$ (mean \pm standard deviation) days. In three cases the 20000 IU daily regimen was insufficient. Two patients with transient ischaemic attacks of cardiac 
origin had the severity and number of episodes decreased by this regimen, but they only ceased completely after the dosage was increased to 30000 IU daily. One patient with cerebral fat embolism had a deep venous thrombosis in the left lower limb of traumatic origin while on the 20000 IU daily regimen.

There were no bleeding complications. Of 48 patients who survived until a definite clinical situation was achieved, 35 were thought to be improved by heparin and were started on coumarin anticoagulants. Of these, 21 were of the cardiogeric embolism group.

\section{COMMENTS}

Full immediate anticoagulation in cardiogenic cerebral embolism has been demonstrated to be safe if a haemorrhagic component is excluded by computerized axial tomography 9 . The present study supports such findings since there were no complications in 22 patients with cardiogenic cerebral embolism. With respect to the efficacy of the regimen these results confirm previous findings 2,13 that close monitoring of coagulation tests may not be critical, since in the two cases in whom further cardiogenic embolization was diagnosed clinically raising of the dose of heparin was efficient in terminating the episodes.

The efficacy of the regimen advocated here, i.e., $20000 \mathrm{IU}$ daily divided in three hourly intravenous injections is more difficult to evaluate in the remaining 28 patients with cerebral ischaemia due to supra-aortic or intra-cranial thrombo-embolic phenomena, because the rate of re-embolization or the course of the neurological deficit is less predictable. The risk of non-cardiac recurrent transient ischaemic attacks developing into completed strokes is highest in the first week 10. None of the patients with transient ischaemic attacks in this study developed a completed stroke while on heparin. In fact the only vascular event in non-cardiogenic embolism was deep venous thrombosis in a severely fractured lower limb. At any rate the regimen proposed here did not produce major bleeding complications as reported in previous studies $\mathbf{3 , 6 , 1 4}$.

Correct evaluation of the risk/benefit ratio of anticoagulation in acute ischaemic cerebro-vascular disease due to thromboembolic phenomena of supra-aortic or intra-cranial arteries will need a controlled study in which a group of patients does not receive anticoagulation. Nonetheless, the results of the present study suggest that a regimen of $2500 \mathrm{IU}$ of heparin given intravenously every three hours is safe in all kinds of acute ischaemic cerebro-vascular disease, without close monitoring of coagulation tests. It should be emphasized that this was demonstrated in a group of 50 patients which included 17 cases with blood pressures above $160 / 95$ at the start of therapy as well as 13 patients above 65 years of age. It is thus suggested that old age, and moderate or severe hypertension do not formally contra-indicate anticoagulation, if reasonable control of blood pressure is achieved within a few hours. We thus recommend that $2500 \mathrm{IU}$ of heparin given intravenously every 3 hours is used in the treatment of acute cerebral ischaemia of any kind, if a haemorrhagic component can be excluded by computerized axial tomography, unless continuous infusion 
and clotting monitoring are available routinely to the large numbers of such patients admitted to general hospitals.

\section{SUMMARY}

The risk/benefit ratio of acute anticoagulation in ischaemic cerebro-vascular disease is not clearly established. A simple and safe intermittent intravenous heparin regimen (20000 IU daily) was used prospectively in 50 patients of $57 \pm 14(\mathrm{~m} \pm \mathrm{sd})$ years of age whose blood pressures ranged from normal to severe hypertension. Twenty-two patients had cardiogenic embolism and the remaining had recurrent severe transient ischaemic attacks of recent onset or progressive cerebral infarcts. Time of exposure to heparin was $6.4 \pm 4(\mathrm{~m} \pm \mathrm{sd})$ days. Two patients had recurrences of cerebral thromboembolism and none had bleeding complications. This is a safe and efficient method of anticoagulation for patients with cerebral ischaemia when continuous infusion of heparin or close monitoring of clotting times are not used routinely.

\section{RESUMO}

Regime simples e seguro de heparina para isquemia aguda.

A relação entre risco e benefício de anticoagulação imediata em doença cerebrovascular isquêmica é discutivel. Um regime simples e seguro de administração endovenosa de heparina $(20000 \mathrm{lU} /$ dia $)$ foi utilizado prospectivamente em 50 pacientes de $57 \pm 14$ (média \pm desvio padrão) anos de idade cujas pressões arteriais variaram de normais a hipertensão severa. Vinte e dois dos pacientes sofreram embolia cerebral cardiogênica e o restante ataques isquêmicos transitórios de inicio recente ou infartos cerebrais progressivos. $O$ tempo de exposição à heparina foi de $6,4 \pm 4$ (média \pm desvio padrão) dias. Dois pacientes tiveram recorrência de tromboembolismo cerebral e nenhum teve complicaçōes hemorrágicas. Este parece ser um método seguro e eficiente de anticoagulação para pacientes com isquemia cerebral aguda, quando infusão contínua de heparina ou monitorização de testes de coagulação frequente não são usados rotineiramente.

\section{REFERENCES}

1. BITTENCOUR', P.R.M.; GIAMBERARDINO, E.; PRECOMA, D. \& MAZER, S. - Fisiopatologia de doenças cerebro-vasculares isquêmicas. Rev. neurol. Argent. $9: 95,1983$.

2. DEYKIN, D. - Heparin therapy: regimens and management. Drugs 13:46, 1977.

3. DRAKE, M.E. \& SHIN, C. - Conversion of ischaemic to haemorrhagic infarction by anticoagulant administration. Arch. Neurol. 40:44, 1983.

4. RASTON, J.D. \& SHERMAN, D.G. - Management of cerebral embolism of cardiac origin. Stroke 11:433, 1980.

5. FIELDS, W.S. - Aspirin for prevention of stroke. J. Med. 14:61, 1983. 
6. FURLAN, A.J.: CAVALIER, S.J.; HOBBS, R.E.; WEINSTEIN, M.A. \& MODIC, M.T. - Haemorrhage and anticoagulation after nonseptic embolic brain infarction. Neurology 32:280, 1982.

7. GENTON, E. - Guidelines for heparin therapy. Ann. int. Med. 80:77, 1984.

8. GENTON, E.; BARNETT, H.J.M.; FIELDS, W.S.; GENT, M. \& HOAK, J.C. - Cerebral ischaemia: the role of thrombosis of antithrombotic therapy. Stroke $8: 150,1977$.

9. LODDER, J. \& van der LUGT, P.J.M. - Evaluation of the risk of immediate anticoagulant treatment in patients with embolic stroke of cardiac origin. Stroke 14:42, 1983.

10. MARSHALL, J. - The cause and prognosis of strokes in people under 50 years. J. neurol. Sci. 53:473, 1982.

11. MILLIKAN, C. - Anticoagulant treatment to prevent cerebral infarction. Med. clin. North America 63:897, 1979.

12. RUFF, R.L. \& DOUGHERTY, J.H. - The evaluation of acute cerebral ischaemia for anti-coagulant therapy: computed tomography or lumbar puncture. Neurology $31: 736,1981$.

13. SALZMAN, E.W.; DEYKIN, D.; SHAPIRO, R.M. \& ROSEMBERG, R. - New Engl. J. Med. 292:1046, 1975.

14. SILVERSTEIN, A. - Neurological complications of anticoagulation therapy. Arch. int. Med. $139: 217,1979$.

Unidade de Neurologia Clinica, Hospital Nossa Senhora das Graças - Rua Alcides Munhoz, 493 - 80.000 - Curitiba, PR - Brasil. 